\title{
Assessment of hemodialysis adequacy: correlation between online clearance monitoring and single pool Kt/V.
}

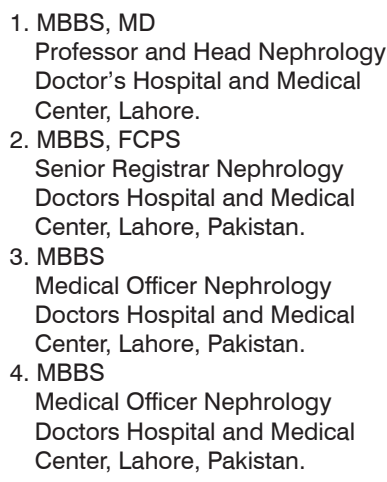

Correspondence Address: Dr. Sidra Saleem

Department of Nephrology

Doctors Hospital and Medical Center Lahore, Pakistan

sidrasaleem73@hotmail.com

Article received on: 01/02/2020 Accepted for publication: 03/06/2020

\begin{abstract}
Abeera Mansur ${ }^{1}$, Sidra Saleem ${ }^{2}$, Asad Mahmood ${ }^{3}$, Zain Rasool ${ }^{4}$
ABSTRACT... Objectives: The aim of this study is to correlate the dose of dialysis delivered by both methods in the dialysis population in our developing country. Study Design: Cross Sectional study. Setting: Dialysis Centre at Doctor's Hospital and Medical Center Lahore. Period: February 1, 2018 to April 30, 2018. Material \& Methods: Using Fresenius 4008S machines equipped with OCM, we prospectively studied 41 hemodialysis patients. All patients were on hemodialysis for more than three months. Pre and post dialysis urea samples were collected for estimation of single pool Kt/V and compared with OCM. Results: The average age of the patients was $56.46 \pm 13.82$ years and the mean duration of dialysis was $28.9 \pm 35.22$ months. Mean blood flow rate was $309.27 \pm 46.06 \mathrm{~mL} / \mathrm{min}$. The mean $\mathrm{Kt} / \mathrm{V}$ was $1.51 \pm 0.216$ $(<p=0.001)$ and the mean OCM was $1.47 \pm 0.191(<p=0.001)$. We found a positive correlation between the two parameters i.e a Pearson's Correlation: $0.83(<p=0.001)$ and an $R$ square value of 0.645 .We found that $\mathrm{OCM}$ is a good indicator of $\mathrm{Kt} / \mathrm{V}$. However, it underestimated $\mathrm{Kt} / \mathrm{V}$ by $2.07 \% \pm 8.53 \%$. Conclusion: Online $\mathrm{Kt} / \mathrm{V}$ calculated by ionic dialysance is a useful method to estimate dialysis dose without the need of blood samples. In clinical practice Kt/V is done on a monthly basis. Any change in the dialysis prescription would entail repeat labs. OCM can be performed at each dialysis session at no extra cost and in real time. Thus, it can prove to be a helpful and economical tool in the assessment of dialysis adequacy in the low income countries with limited resources.
\end{abstract}

Key word: $\quad$ Comparison, Dialysis Adequacy, Hemodialysis, KT/V, OCM Online Clearance Monitoring.

Article Citation: Saleem S, Mansur A, Mahmood A, Rasool Z. Assessment of hemodialysis adequacy: Correlation between online clearance monitoring and single pool Kt/V. Professional Med J 2020; 27(11):2407-2413. https://doi.org/10.29309/TPMJ/2020.27.11.4534

\section{INTRODUCTION}

Numerous studies in dialysis patients have shown that morbidity and mortality is highly affected by the delivered dialysis dose..$^{1,2}$ Furthermore, it has been demonstrated in many studies that patient outcomes are improved with more efficient dialysis. $3,4,5$ In clinical practice, evaluation of delivered dose in maintenance hemodialysis is done by measuring serum urea in blood samples to determine $\mathrm{Kt} / \mathrm{V}$. $\mathrm{Kt} / \mathrm{V}$ is a dimensionless ratio used to quantify hemodialysis, where $\mathrm{Kt}$ is described as the clearance of urea by the dialyser $(\mathrm{K})$, time of the dialysis treatment ( $\mathrm{t}$, in minutes) and $\mathrm{V}$ is the volume of distribution of urea in milliliters which is presumed to be similar to total body water (TBW) corrected for volume lost during ultrafiltration. Kt is affected by the concentration of urea in the pre and post dialysis samples, the dialyzer size, the blood and dialysate flow. The changes in Urea levels are used to identify the efficiency of dialysis. Urea has high levels in hemodialysis patients, can be easily measured, has a high volume of distribution and can be easily dialysed. $6,7,8$

To find $\mathrm{Kt} / \mathrm{V}$ the most widely used hypothesis is that urea is considered to be distributed in one chamber of the body. The concept behind singlepool Kt/V (spKt/V) is that there is a speedy decrease in urea and a rapid equilibrium is established between the blood and tissue chambers after dialysis. ${ }^{9}$ Other methods include double pool sampling methods and equilibrated $\mathrm{Kt} / \mathrm{V}$. These models are not convenient as a separate test 
of BUN needs to be performed 30 minutes post dialysis, which is rather cumbersome for many patients as they would have to stay behind after dialysis.

According to the National Kidney Foundation's Kidney Disease Outcomes Quality.

Initiative (KDOQI) guidelines of 2015, it has been reinforced the delivered dose of HD should be measured at regular intervals no less than monthly. ${ }^{10}$

The currently recommended minimum target of spKt/Vis greater than or equal to 1.2 with an optimal level of 1.4. Sp Kt/V of at least 1.2 is associated with better quality of life and mortality in patients who are on thrice weekly dialysis regimen. ${ }^{11,12}$

Prescribing a dialysis dose does not ensure the adequate delivery of dialysis due to multiple barriers involved both on the part of the clinical institution and the patients themselves. ${ }^{13,14}$

To rectify this problem, several methods with variable difficulty of execution have been devised so that the procedural inefficiencies can be rectified on a monthly basis/treatment by treatment basis or intra-session basis.

Dialysis machines now come equipped with probes that can estimate the motion of ions through the dialyzer membrane and to find out the amount of dialysis dose delivered.

On newer model dialysis machines (like Diascan ${ }^{\circledR}$ Hospal-gambro; OCM; Fresenius), we can measure conductivity through online clearance monitors. ${ }^{15,16}$

The principle used to measure conductivity involves using a pair of sensors to detect conductivity at the dialyzer inlet and outlet. These measure the changes in concentration in the dialysis fluid. The highest percentage of easily movable electrolyte in the dialysate is the Sodium ions. The concentration of sodium therefore determines the total conductivity of the dialysis fluid. The in-vitro and in-vivo diffusion characteristics of both sodium and urea exhibit across a dialysis membrane are similar.

By measuring conductivity at the inlet and outlet of the dialyzer by sensors, sodium ion concentration is indirectly measured in the dialysis solution. The sensors are mutually independent temperature compensated conductivity cells. ${ }^{17}$

Using these measures we can find the diffusion profile of sodium ion through the dialyzer and therefore be able to calculate the ionic clearance. (D) As Sodium moves from high concentration in the dialysate to lower concentration in the blood, the conductivity of the dialyser decreases at the outlet of the dialyzer.

Since sodium and urea diffusion traits are similar, urea clearance can be determined by using the dialysance of Sodium. ${ }^{18}$ Conductivity clearance is determined by comparing the changes in conductivity at the end to baseline conductivity.

$\mathrm{Kt} / \mathrm{V}$ is not routinely done in our dialysis population because of limited resources, therefore, comparison between OCM and $\mathrm{Kt} / \mathrm{V}$ has not been studied in our setting. As OCM helps physicians and nursing staff to ensure and document on a regular basis that the renal replacement therapy meets the recommended or required dialysis clearance without the need for additional laboratory tests or expenses, it would be really helpful as an alternative tool to measure dialysis adequacy in our hemodialysis patients.

The aim of our study was to compare sp Kt/V with Online Clearance Monitoring using Fresenius 4008 machine in our dialysis population and to determine whether OCM can be an effective alternative tool for $\mathrm{Kt} / \mathrm{V}$.

\section{MATERIAL \& METHODS}

This was a single center, cross sectional study done on End stage renal disease Patients who were having maintenance hemodialysis at the Dialysis Centre at Doctor's hospital and medical center for at least three months. Patients with Acute Kidney Injury were excluded. Informed 
consent was taken from all patients after IRB Approval.

Fresenius 4008S machines that measured OCM, was used for this study. Samples for measuring blood urea levels at the start and end of dialysis were collected for estimation of Single pool Kt/N. The blood sample at the start of dialysis for BUN was drawn before injecting saline, heparin, or other potential diluents from the arterial line. The blood sample at the end of dialysis was taken from the dialyzer inflow port using a decreasedflow method (Blood flow rate of $100 \mathrm{~mL} / \mathrm{min}$ for 15 seconds) and setting the ultrafiltration rate to zero. The ultrafiltration volume and the post dialysis weight were recorded for the calculation of sp Kt/V and compared with OCM.

OCM was measured by first estimating the volume of distribution of urea $V$ by use of the anthropometric formulae developed by Watson. Using the $\mathrm{OCM}{ }^{\circledR}$ menu of the $4008 \mathrm{~S}$ machine, age in years, height in $\mathrm{cm}$, dry weight in $\mathrm{kg}$ and gender are entered. In addition, Hematocrit and a target $\mathrm{Kt} / \mathrm{V}$ were also entered. The program then proceeds with a timed pulsed increase in conductivity and gives an OCM value at the end of dialysis. The first measurement was taken 15 minutes after the start of dialysis and the last one occurs 15 minutes prior to the end of dialysis. Four measurements were performed at equal intervals during dialysis. ${ }^{19}$

Data was analyzed using Statistical Package for the Social Sciences (SPSS) for Windows software package release 25. Data was expressed as mean and standard deviation. A p-value of $\leq 0.05$ was considered significant.

The value of $\mathrm{Kt} / \mathrm{V}$ and $\mathrm{CM}$ were expressed as mean with Standard deviation.

\section{RESULTS}

Forty one hemodialysis patients from February 1st, 2018 to April 30th, 2018 were evaluated. The minimum duration of follow up was three months. The study population consists of 18 males and 23 females. Their mean age was $56.46 \pm 13.82$ years and mean duration of dialysis was 28.9 \pm 35.22 months. There were 26 patients with diabetic nephropathy, 32 hypertensive patients and 3 patients with glomerulonephritis as shown in Table-l.

\begin{tabular}{|l|c|}
\hline \multicolumn{1}{|c|}{ Characteristic } & Mean \\
\hline Age(years) & $56.46 \pm 13.82$ \\
\hline Duration of dialysis(months) & $28.9 \pm 35.21$ \\
\hline Patients with DM & $26(63.4 \%)$ \\
\hline Patients with HTN & $32(78 \%)$ \\
\hline Patients with GN & $3(0.07 \%)$ \\
\hline
\end{tabular}

Table-I. Patient characteristics.

Mean blood flow was $309.27 \pm 46.06 \mathrm{~mL} /$ minute. Dialysate flow in all patients was $500 \mathrm{ml} / \mathrm{min}$. Eight patients were using a tunneled catheter (19.5\%), 3 had an AV Graft (0.073\%) and 30 had a functioning Arteriovenous fistula (73.1\%). $85.4 \%(n=35)$ of the population was prescribed the FX10 dialysis media, $9.8 \%(n=4)$ were using FX100 and $4.9 \%(n=2)$ were using F8HPS filter. $7.3 \%(n=3)$ patients had once weekly dialysis, $70.7 \%(n=29)$ patients had twice weekly dialysis and $22 \%(n=9)$ patients underwent thrice weekly hemodialysis as shown in Table-II. Variation in the frequency of hemodialysis per week was due to noncompliance. Average duration of dialysis was four hours per session.

\begin{tabular}{|c|c|c|}
\hline \multicolumn{2}{|c|}{ Characteristic } & Mean \\
\hline \multicolumn{2}{|l|}{ Dry weight(kg) } & $70.13 \pm 16.07$ \\
\hline \multicolumn{2}{|l|}{$\mathrm{OCM}$} & $1.47 \pm 0.191$ \\
\hline \multicolumn{2}{|l|}{$\mathrm{Kt} / \mathrm{V}$} & $1.51 \pm 0.2165$ \\
\hline \multicolumn{2}{|l|}{ URR(\%) } & $71.7 \pm 6.25$ \\
\hline \multirow{3}{*}{$\begin{array}{l}\text { Frequency of } \\
\text { hemodialysis }\end{array}$} & 1/WEEK & 3 \\
\hline & 2/WEEK & 29 \\
\hline & 3/WEEK & 9 \\
\hline \multirow{4}{*}{ Access } & L/AVF & 20 \\
\hline & $\mathrm{R} / \mathrm{AVF}$ & 10 \\
\hline & Permanent Catheter & 8 \\
\hline & L/Arterio Venous graft & 3 \\
\hline
\end{tabular}

Mean Kt/V was $1.51 \pm 0.216(p=<0.001)$ and mean OCM was $1.47 \pm 0.191(p=<0.001)$. We found a positive correlation between the two parameters i.e a Pearson's Correlation: 0.83 
$(p=<0.001)$ and an $R$ square value of 0.645 (Figure-1).

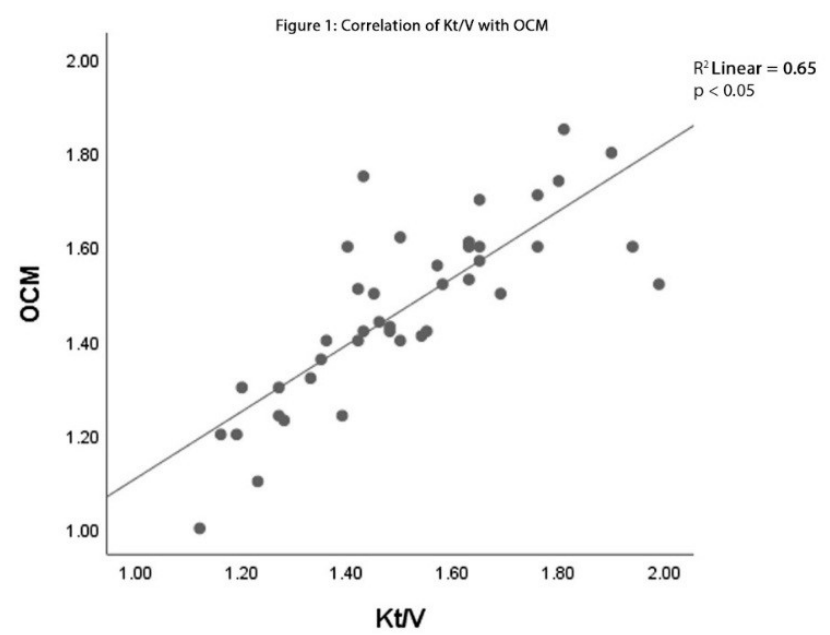

Figure-1. Correlation of $\mathrm{Kt} / \mathrm{V}$ and $\mathrm{OCM}$.

We found that OCM is a good indicator of $\mathrm{Kt} / \mathrm{V}$. However, it underestimated Kt/V by $2.07 \% \pm 8.53 \%$. There was a positive correlation between OCM and URR with an $\mathrm{R}$ square value of 0.388 with $p<0.05$ as shown in Figure- 2 .

None of the patients exhibited excessive thirst, cramps, nausea, vomiting, increase in blood pressure or increased intradialytic weight gain. Immediate post dialysis $\mathrm{Na}+$ measurement was not done.

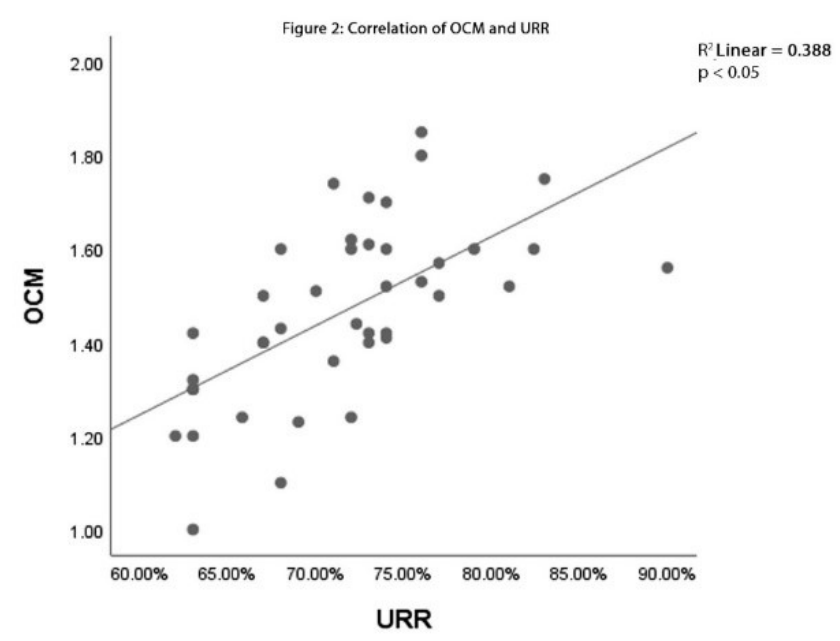

Figure-2.

On further analysis we found a positive correlation between Kt/N and URR with an R square value of $0.523(p=<0.001)$ as shown in Figure-3.

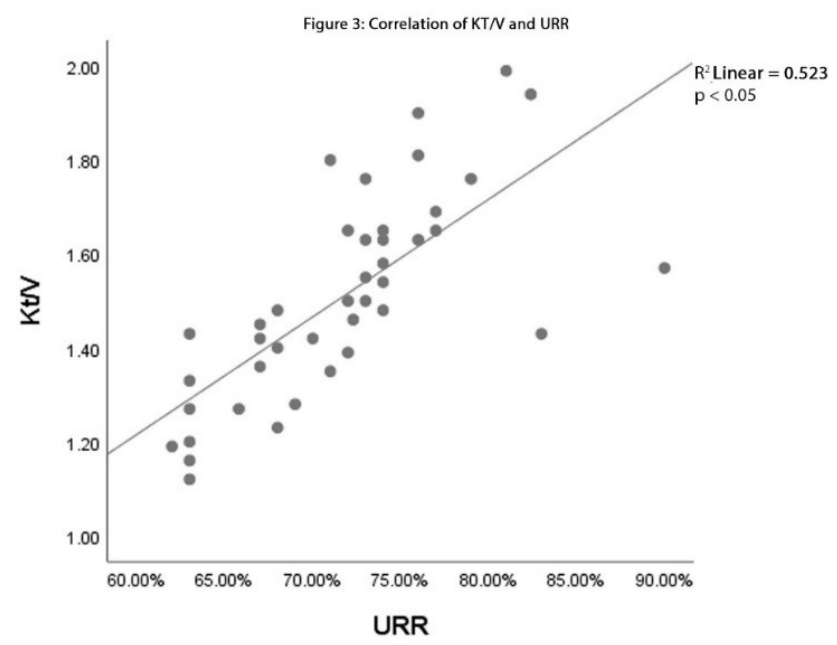

Figure-3

The average URR was $71.70 \%$ with a Standard deviation of \pm 6.25 . Range is $28 \%$ with maximum URR of $90 \%$ and minimum URR of $62 \%$.

\section{DISCUSSION}

There are many methods used to evaluate delivery of dialysis in extracorporeal dialyzing systems. Other online methods available are: Ion selective electrodes, ultraviolet absorbance and flame photometry. Selectivity to a single ion is hard in the Ion selective electrode method as there is mixing from other ions and frequent recalibration is needed. ${ }^{20}$ Flame photometry is bulky. ${ }^{21}$

Ongoing real time determination of dialysis dose can also be done by analyzing the spent dialysate- Adimea (B. Braun Avitum). ${ }^{22}$ Ultraviolet absorbance is commercially available, dependent on the size of solute and has limited ion-selectivity. UV light is used to determine the rate at which solutes are removed from the blood via an optical sensor attached to the drain output of the dialysis machine. (DiaSens). ${ }^{23}$

There are many other studies that have attempted correlation between $\mathrm{Kt} / \mathrm{V}$ and OCM. Using Fresenius 4008 Kuhlman et $\mathrm{al}^{24}$ and Sujit ${ }^{25}$ et al were able to show a correlation of 0.87 and 0.964 . Steil et al (18) showed an in vitro correlation of 0.998 . Other studies showed a correlation of 0.92$0.96^{26,27}$, with a decrease in correlation at higher 
clearance values.

In another study in Pakistan, there was a correlation of 0.8 between $\mathrm{Kt} / \mathrm{V}$ and $\mathrm{OCM}$ using Fresenius $4008 \mathrm{~S} / \mathrm{H}^{28}$

The studies that had poor correlation, suggested that there may have been an erroneous $\mathrm{V}$ calculation. ${ }^{29,30}$ In a paper evaluating various studies, Aslam et $\mathrm{al}^{31}$ concluded that the various online methods available for dialysis adequacy provide a reliable and safe technique while providing excellent correlation with $\mathrm{Kt} / \mathrm{V}$.

Our study showed a correlation of 0.83 . None of the patients exhibited excessive thirst, cramps, nausea, vomiting, increase in blood pressure or increased intradialytic weight gain. Immediate post dialysis $\mathrm{Na}+$ measurement was not done.

Online Continuous Monitoring (OCM) avoids blood draws thus avoiding the collection of samples. Measuring adequacy using urea is time consuming and involves the use of needles, exposure of staff and patients to blood and considerable effort in processing and analyzing blood samples. As OCM is measured by probes installed within the dialysis machine (machine variant) no extra labs have to be engaged and this can be measured at fixed intervals and can be used to lengthen or shorten the dialysis session if the physician perceives that the required dose of dialysis is not being delivered. $\mathrm{Kt} / \mathrm{V}$ is usually done only once a month. OCM can be done multiple times and the dialytic treatment can be adjusted with no extra expense. Adjustment can be done by increasing the blood flow, increasing the dialyzer size, increasing the duration of dialysis, adjusting the dialyzer needles size and placement and reevaluating the AV access.

The need for demanding tests can be avoided once the relation between calculated $\mathrm{Kt} / \mathrm{V}$ and Online $\mathrm{Kt} / \mathrm{V}$ is understood on a patient by patient basis.

Thus, making it easier to evaluate the delivery of dialysis per session and provide the patients with the most mortality benefit by using the least amount of resources and detaining the patient at the dialysis facility for the least amount of time possible.

Using this method will enable us to achieve the objective of developing a low cost method of monitoring clearance and to quantify the correlation between sp Kt/V and OCM.

Although this method has been commercialized and integrated in dialysis machine for ionic dialysance measurement of $\mathrm{Na}$, there are some disadvantages. The one disadvantage of conductivity measurement is that it is not specific for ion type distinction and therefore it only enables an approximate calculation of plasma conductivity as a surrogate of plasma sodium. ${ }^{32,33}$ In addition there may be interference, drift over time.

At present there is a lack of studies that evaluate outcome of patients using OCM. OCM measurement is also not part of the current DOQI guidelines. Long term relationship of adequate OCM with cardiovascular disease, nutrition, mineral and bone disease, metabolic acidosis and mortality needs to be evaluated.

\section{Conclusion}

Online $\mathrm{Kt} / \mathrm{V}$ calculated by ionic dialysance is a useful method to estimate dialysis dose without the need of blood samples. In clinical practice $\mathrm{Kt} / \mathrm{V}$ is done on a monthly basis. Any change in the dialysis prescription would entail repeat labs. OCM can be performed at each dialysis session at no extra cost and in real time. Thus, it can prove to be a helpful and economical tool in the assessment of dialysis adequacy in the low income countries with limited resources.

Copyright $\subset 03$ June, 2020.

\section{REFERENCES}

1. Lowrie, E.G., Laird, N.M, PArker, T.F., and Sargent, J.A. Effect of the hemodialysis prescription of patient morbidity: Report from the National Cooperative Dialysis Study. N Engl J Med. 1981; 305: 1176-1181. 
2. Hakim, Raymond M, Breyer, J, Ismail N, Schulman G. Effects of dose of dialysis on morbidity and mortality." American Journal of Kidney Diseases, vol. 23, no. 5, 1994, pp. 661-669.

3. Parker TF, Husni L, Huang W, Lew N, Lowrie EG. Survival of hemodialysis patients in the United States is improved with a greater quantity of dialysis. AJKD 1994; 23(5):670-80.

4. Held PJ, Port FK, Wolfe RA, Stannard DC, Carroll CE, Daugirdas JT, et al. The dose of hemodialysis and patient mortality. Kidney International. 1996; 50(2):5506.

5. Parker TF. Role of dialysis dose on morbidity and mortality in maintenance hemodialysis patients. Am J Kidney Dis. 1994 Dec; 24(6):981-9.

6. Locatelli $F$, Buoncristiani $U$, Canaud $B$, Köhler $H$, Petitclerc T, Zucchelli P. Dialysis dose and frequency. Nephrol Dial Transplant. 2005; 20(2):285-296.

7. KDOQI Clinical practice guidelines and clinical practice recommendations for 2006 updates: Hemodialysis adequacy, peritoneal. Am J Kidney Dis. 2006; 48:S1-S322.

8. Depner TA. Uremic toxicity: Urea and beyond. Semin Dial. 2001; 14(4):246-251.

9. Daugirdas JT. Second generation logarithmic estimates of single-pool variable volume $\mathrm{Kt} / \mathrm{V}$ : an analysis of error. J Am Soc Nephrol 1993; 4(5) 120513.

10. National Kidney Foundation. KDOQI clinical practice guideline for hemodialysis adequacy: 2015 update. Am J Kidney Dis. 2015; 66(5):884-930.

11. Eknoyan G1, Beck GJ, Cheung AK, Daugirdas JT, Greene T, Kusek JW, Allon M, Bailey J, Delmez JA, Depner TA, Dwyer JT, Levey AS, Levin NW, Milford E, Ornt DB, Rocco MV, Schulman G, Schwab SJ, Teehan $\mathrm{BP}$, Toto R; Hemodialysis (HEMO) study group "Effect of dialysis dose and membrane flux in maintenance hemodialysis". The New England Journal of Medicine. 2002. 347(25):2020-2019.

12. KDOQI Clinical practice guideline for hemodialysis adequacy: 2015 Update. AJKD November 2015 Volume 66, Issue 5, pages 884-930.

13. Palevsky PM, Washington MS, Stevenson JA, Rohay JM, Dyer NJ, Lockett R, Perry SB. Barriers to the delivery of adequate hemodialysis in ESRD Network 4. Adv Ren Replace Ther. 2000 Oct; 7(4 Suppl 1):S11-20.
14. Sehgal AR, Snow RJ, Singer ME, Amini SB, DeOreo PB, Silver MR, Cebul RD. Barriers to adequate delivery of hemodialysis. Am J Kidney Dis. 1998 Apr; 31(4):593601.

15. Petitclerc T. Do dialysate conductivity measurements provide conductivity clearance or ionic dialysance Kidney Int. 2006; 70:1682-1686.

16. Gotch FA, Panlilio FM, Buyaki RA, et al. Mechanisms determining the ratio of conductivity clearance to urea clearance. Kidney Int Suppl. 2004; 66:S3-S24.

17. Polaschegg HD: Automatic, noninvasive intradialytic clearance measurement. Int J Artif Organs 1993; 16(4): 185-191.

18. Steil $H$, Kaufman AM, Morris AT, Levin NW, Polaschegg HD: In vivo verification of an automatic noninvasive system for real time Kt evaluation. ASAIO J 1993; 39(3): M348-52.

19. Online clearance monitoring. fmc-au.com 15 B 2014.

20. International Electrochemical Commission. Medical electrical equipment-part 2-16: particular requirements for the basic safety and essential performance of haemodialysis, hemodiafiltration and hemofiltration equipment. Geneva (Switzerland): International Electrochemical Commission IEC; 2012.

21. BWB Technologies. Available from: http://www. bwbtech.com/bwb_xp_flame_photometers_ products.htm.

22. Adimea Real-time monitoring of the dialysis dose for optimising the treatment quality; 2016 Jun. Available from: http://www.bbraun-dialysis.com/cps/rde/xchg/avdialysis.

23. Measurement of Dialysis Adequacy. Available from: http://Idiamon.eu/products/measurement-ofdialysis-adequacy.

24. Kuhlmann U, Goldau R, Samadi N, et al. Accuracy and safety of online clearance monitoring based on conductivity variation. Nephrol Dial Transplant. 2001; 16:1053-1058.

25. S. Sujit, R. Vivek Praveen, J. Jaya Nivash, N.D. Srinivasa Prasad, S. Thirumavalavan, M. Edwin Fernando. Comparison of $\mathbf{k t} / \mathbf{v}$ in haemodialysis by daugirdas method and by online clearance monitoring. Losr journal of dental and medical sciences (iosr-jdms) e-issn: 2279-0853, p-issn: 2279-0861.volume 16, issue 5 ver. li (may. 2017), pp 134-137.

26. Goldau R, Kuhlmann U, Samadi N, et al. Ionic dialysance measurement is urea distribution volume dependent: A new approach to better results. Artif Organs.2002; 26:321-332. 
27. Lindsay RM, Bene B, Goux N, Heidenheim AP, Landgren C, Sternby J. Relationship between effective ionic dialysance and in vivo urea clearance during hemodialysis. Am J Kidney Dis. 2001; 38:565-574.

28. Hussain A, Shabeer $H$, Ahmed A. Assessment of adequacy of hemodialysis and nutritional status in patients on maintenance hemodialysis at Dialysis Centre Sheikh Zayed Hospital Rahim Yar Khan PJMHS Vol. 9, No. 4, 2015 1319-24.

29. Al Saran K, Sabry A, Abdulghafour,M, Yehia A. Online conductivity monitoring of dialysis adequacy versus $\mathrm{Kt} / \mathrm{V}$ derived from urea reduction ratio: A prospective study from a Saudi Center. Ren Fail. 2010; 32:36-40.

30. Marsenic O, Booker K, Studnicka K. Use of ionic dialysance to calculate $\mathrm{Kt} / \mathrm{V}$ in pediatric hemodialysis. Hemodial Int. 2011; 15:S2-S8.
31. Aslam S, Saggi SJ, Salifu M, Kossmann RJ. Online measurement of hemodialysis adequacy using effective ionic dialysance of sodium-a review of its principles, applications, benefits, and risks. Hemodialysis International. 2018 Oct;22(4):425-34.

32. Bosetto A, Bene B, Petitclerc T. Sodium management in dialysis by conductivity. Adv Ren Replace Ther. 1999; 6:243-254.

33. Moret KE, Beerenhout $\mathrm{CH}$, Kooman JP. Variations in predialytic plasma conductivity in dialysis patients: Effect on ionic mass balance and blood pressure. Asaio J. 2011; 57:53-61.

\begin{tabular}{|c|c|c|c|}
\hline \multicolumn{4}{|c|}{ AUTHORSHIP AND CONTRIBUTION DECLARATION } \\
\hline Sr. \# & Author(s) Full Name & Contribution to the paper & Author(s) Signature \\
\hline 1 & Abeera Mansur & 1st Author & Hauro. suanews \\
\hline 2 & Sidra Saleem & 2nd Author & Sidlage \\
\hline 3 & Asad Mahmood & 3rd Author & Clselmannow \\
\hline 4 & Zain Rasool & 4th AUthor & Rarigoil \\
\hline
\end{tabular}

